\title{
Paediatric emergency and acute care in resource poor settings
}

* Professor Trevor Duke, MD FRACP

Centre for International Child Health

Department of Paediatrics, University of Melbourne

Royal Children's Hospital, Melbourne

Adjunct Professor of Child Health, University of PNG

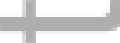

Email: trevor.duke@rch.org.au

Telephone: +6139345 5968

* Corresponding author

Dr. Baljit Cheema

Paediatric Emergency Specialist

Emergency Medical Services

Western Cape Health

Senior Lecturer, Division of Emergency Medicine

University of Cape Town

Word count 2254

Review article

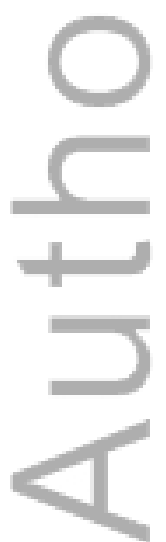

This is the author manuscript accepted for publication and has undergone full peer review but has not been through the copyediting, typesetting, pagination and proofreading process, which may lead to differences between this version and the Version of Record. Please cite this article as doi: 10.1111/jpc.13105

This article is protected by copyright. All rights reserved. 


\section{Paediatric acute care in resource poor settings}

Acute care of seriously ill children is a global public health issue, and there is much scope for improving quality of care in hospitals at all levels in many developing countries. We describe the current state of paediatric emergency and acute care in the least developed regions of low and middle income countries and identify gaps and requirements for improving quality. Approaches are needed which span the continuum of care: from triage and emergency treatment, the diagnostic process, identification of comorbidities, treatment, monitoring and supportive care, discharge planning and follow-up. Improvements require support and training for health workers and quality processes. Effective training is that which is ongoing, combining good technical training in undergraduate courses, and continuing professional development. Quality processes combine evidencebased guidelines, essential medicines, appropriate technology, appropriate financing of services, standards and assessment tools and training resources. While initial emergency treatment is based on common clinical syndromes, early differentiation is required for specific treatment, and this can usually be done clinically without expensive tests. While global strategies are important, it is what happens locally that makes a difference and is too often neglected. In rural areas in the poorest countries in the world, public doctors and nurses who provide emergency and acute care for children are revered by their communities, and demonstrate daily that much can be done with little.

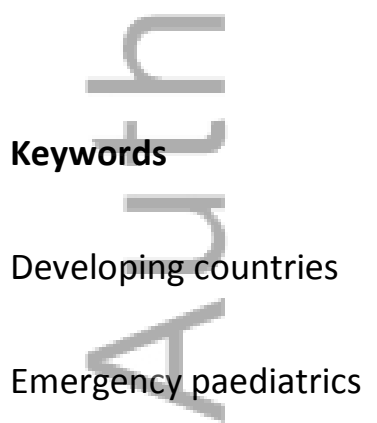

Acute paediatric care

This article is protected by copyright. All rights reserved. 
Rural health

Hospital care for children

\section{Key points}

1. The quality of emergency and acute care for children in health facilities in developing countries is a global and local public health issue

2. Management of common clinical paediatric emergency syndromes, and early clinical differentiation of some specific diagnoses are needed to improve care and reduce mortality

3. Improvements in quality of care should be holistic, addressing the common deficiencies in care and covering all the stages of management, but improvements do not need to be expensive.

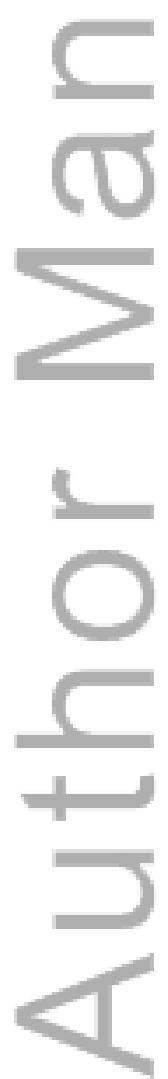

This article is protected by copyright. All rights reserved. 


\section{Introduction}

The challenges of emergency and acute paediatric care vary between and within low and middle income countries, varying as much as the differences in health resources and disease epidemiology. At one end of a spectrum are well-resourced hospitals in large cities in China, India, South America and the Middle East, where the ambitions for emergency and intensive care are similar to those in Western Europe, Australia or North America. In these settings, facilities and equipment are afforded, and many of the current challenges are related to capacity and "developing the specialty" of emergency or intensive care medicine in post-graduate medical and nursing training programs. At the other end of the spectrum are rural hospitals or clinics in the least developed countries, countries characterised by Paul Collier as 'The Bottom Billion", ${ }^{1}$ where even the basics of emergency care - a system of triage, guidelines for the management of common illnesses, oxygen and emergency drugs, basic equipment and appropriately trained staff are rarely available. Many of the least-developed settings are in rural Africa, but similar environments exist in the poorer areas of developing countries in Asia and the Pacific region. These regions are characterised by high child mortality, high neonatal mortality, a predominance of infectious diseases, difficulty accessing healthcare, and traditionally rural populations. Within remote or rural areas of low-middle income countries, health services have remained undeveloped, there is difficulty retaining staff and many of the ingredients of basic emergency care and quality processes are also not present or not working. The urbanisation of the $21^{\text {st }}$ century means such environments now also exist in many cities and towns.

Paediatric emergency care does not need to be expensive, nor overly reliant on high technology. Emergency care is about early recognition of serious illness or injury, and timely intervention, and as much about prevention of harm as it is about treatment of disease. It can be holistic even if the 
focus is on saving lives. And emergency care begins in the community, with the recognition of serious illness and prompt care seeking, referral and safe transport.

At least $10 \%$ of children assessed in primary care using the World Health Organization's Integrated Management of Childhood IIIness (IMCI) strategy need referral for a higher level of care, ${ }^{2}$ so good quality primary care services and first referral-level are essential for curative health services to have an optimal impact on population health.

-

The World Health Organization has an approach to paediatric emergency care called ETAT (Emergency Triage, Assessment and Treatment). This is embedded in an overall approach outlined in the Pocket Book of Hospital Care for Children; it is a quality improvement approach based on evidence-based guidelines, essential medicines, appropriate technology, standards and assessment tools and training resources. ${ }^{3}$

The stages of Hospital Care for Children, common to all serious illnesses, are: triage, emergency treatment, history, examination, laboratory and radiological investigations if required, diagnoses and differential diagnoses, treatment, monitoring and supportive care, discharge planning, and follow up. Reviews of the quality of paediatric care in many developing countries have highlighted major deficiencies in each of these areas, with much scope for improvement in district-level hospitals. ${ }^{4-8}$ As many hospital deaths occur in the first 24 hours, emergency care will be taken to mean all the acute care that is given in the first 24 hours after presentation, in emergency departments, children's outpatients departments, children's wards and high dependency areas. We describe practical and systems aspects, a detailed discussion of other aspects of acute paediatric conditions is beyond the scope of this paper. Studies from Malawi, Kenya, Papua New Guinea and elsewhere show that improving the systems and training in emergency aspects of care can reduce in-hospital

This article is protected by copyright. All rights reserved. 
mortality. ${ }^{9-11}$ Common problems associated with provision of acute care in these settings are listed in Table 1.

\section{Common acute emergency clinical syndromes in low and middle income countries}

Emergency care initially applies generic approaches to acute clinical syndromes. The commonest of these among children in developing countries are:

- cough and difficult breathing (acute respiratory distress)

- diarrhoeal disease and severe dehydration

- acute (often febrile) encephalopathy

- shock

- severe malnutrition

- poisoning or accidental ingestion

- trauma, burns and injuries

There is overlap between these clinical syndromes: e.g. severe dehydration often presents with tachypnoea from metabolic acidosis, which can be misinterpreted as respiratory distress from pneumonia; severe malaria also presents with tachypnoea. ${ }^{12}$ Furthermore, children often have 1 more than one disease process: pneumonia and diarrhoea; diarrhoea and malnutrition; malaria and severe anaemia. Children with co-morbidities are the most likely to die, partly because of the increased severity of illness and partly because co-morbidities are often missed.

Each of the common clinical syndromes can be expanded to a number of more specific diagnoses. Severe respiratory distress and hypoxaemia is most commonly due to severe pneumonia or severe bronchiolitis, but depending on local epidemiology, asthma, tuberculosis with complications, and HIV with pneumocystis pneumonia may also be common causes. These require generic emergency

This article is protected by copyright. All rights reserved. 
therapies (such as oxygen), but also some differentiation for more specific initial therapy (whether to give bronchodilators or not, whether to start treatment for pneumocystis or not, etc).

Using shock as a more complex example (Table 2), it is possible to understand some of the reasons why generic treatment alone, such as just giving boluses of fluid, are insufficient, and why these may cause harm to some patients. ${ }^{13}$ Although a common reason for shock is severe dehydration from diarrhoeal disease (requiring additional fluid), training and guidelines for the differentiation of the $=$

clinical syndrome of shock to needed to enable specific treatments to be given. ${ }^{3}$ While some therapies for shock (such as inotropes or mechanical ventilation) are rarely available in small hospitals in developing countries, others can be given safely in most first-level referral hospitals and are life-saving. Some examples of therapies (beyond fluids and oxygen) for conditions causing shock that are within the WHO Essential Medicines list and WHO clinical guidelines are listed in the textbox. While generic approaches to clinical syndromes are important, identification of co-morbidities and early differentiation of clinical syndromes are often required to save the lives of seriously ill children.

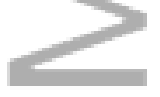

\section{Pre-hospital emergency care and transport services}

Emergency care starts in the community, with care seeking by parents, community health workers recognising severe illness, and first-responders. Training of community health workers in the recognition of serious illness in children can lead to more rapid care seeking and prompt referral. This can substantially reduce mortality from pneumonia and diarrhoea. ${ }^{14}$

This article is protected by copyright. All rights reserved. 
Safe transport is required by many sick children seen in primary care facilities to rural and district hospitals. However, this is not always feasible and this need has to be balanced against risk of transport, distance to referral hospital, costs and the needs of other patients.

Development of a reliable pre-hospital emergency management system (EMS) is part of the ther evolution of the overall emergency care system. An EMS must be carefully planned with the involvement of the relevant national ministries and sub-national health authorities, and $=$

incrementally introduced. The WHO Pre-Hospital Trauma Systems report outlines an approach, encompassing: design, administration, disaster planning, communications, quality improvement, and ethical and legal aspects. A tiered-approach is recommended: Tier 1: care by first responders: basic first-aid providers, and then advanced first-aid providers; Tier 2: basic pre-hospital trauma care and Tier 3: advanced pre-hospital trauma care. ${ }^{18}$

In some countries, transport from primary care to hospitals is even more difficult and other modes of emergency transport are employed: in Tanzania these included bicycles with trailers, tricycles with platforms, motorboats, and ox-carts. ${ }^{15}$ In Ghana, where most pre-hospital transport of trauma victims occurs by taxis and buses, a training course for commercial drivers in airway management, control of external bleeding, splinting of fractures, spinal precautions and triage lead to reported improvements in emergency care. ${ }^{16}$ In Malawi motorcycle ambulances reduced referral delays from remote rural health centres by $2-4$ hrs while being far cheaper to purchase and with minimal annual running costs, compared to car ambulances. ${ }^{17}$

Where referral is not feasible, primary care staff should be trained in acute care (such as the WHO Hospital Care for Children course) and communication technology. Using high frequency radio or mobile phones can mean that consultation with a paediatrician can take place remotely.

This article is protected by copyright. All rights reserved. 


\section{High dependency care}

It is rare to have paediatric intensive care units in district or rural hospitals. In most hospitals the first 24 hours of acute or critical care is provided in emergency or outpatients departments, then in a nir

children's ward. For critically ill children, triage, assessment and emergency care should be continuous with specific treatment, supportive care and close monitoring. Meticulous attention to detail, particularly the prevention of complications is needed in the first 24 hours and beyond. An example of this is in Table 3, which describes some elements of the care of children in coma. Care of such children and those with other acute clinical syndromes (listed above) can be best done by nursing children in a high dependency area within a children's ward.

Where a high dependency area is located depends on organisational issues for a given hospital. In most small hospitals this can be within the children's ward, as there will be a necessary flow of children from the high-dependency area to a non-high-dependency area or general beds, and some children in the general beds will deteriorate, needing oxygen or a higher level of monitoring. Some components of a paediatric high dependency area are listed in Table 4.

In many hospitals it is appropriate to consider higher level respiratory support, such as a method for continuous positive airway pressure (CPAP) or high-flow nasal cannula oxygen therapy. ${ }^{19}$ Simple technologies exist to do this, but require guidelines, training and equipment maintenance. Intensive care, including intubation, mechanical ventilation and inotrope infusions require additional resources, facilities, quality systems, clinical skills, judgement of prognosis and disease reversibility, and an understanding of ethics.

This article is protected by copyright. All rights reserved. 


\section{Some common clinical pitfalls in acute care of children}

- Not differentiating the problem early enough

- Giving too much intravenous fluid or the wrong fluid to children

- Not detecting and treating hypoxaemia

- Not detecting and treating hypoglycaemia

- Inadequate care of the child in coma

- Not recognising and treating co-morbidities

\section{Staffing and training}

The International Labour Organization recently estimated a shortfall of 10.3 million health workers worldwide, with $70 \%$ of this deficit in rural locations. ${ }^{20}$ For many rural health staff ongoing professional development is absent. There are programs to train staff in comprehensive acute care for seriously ill children, including the WHO training program 'Hospital Care for Children', based on the 10 stages of management listed above. This training program has accompanied the implementation of WHO's Hospital Care for Children guidelines in many countries.${ }^{21}$ Other training initiatives such as Emergency Triage and Treatment (ETAT) ${ }^{22}$ and "ETAT-Plus" ${ }^{23}$ have been successful in several countries, as has the Advanced Paediatric Life Support course in some countries. ${ }^{24}$

\section{Other tools}

Newer mobile device technologies are increasingly relevant as phone coverage and tablet technology extends in many developing countries. There are numerous apps for paediatric

This article is protected by copyright. All rights reserved. 
emergency medicine. Some of these are summarised at http://www.ecinsw.com.au/paediatricapps. Others include Palm-EM: http://www.palm-er.com/ and The Open Medicine Project South Africa (http://www.openmedicineproject.org/photo-gallery/emergency-medicine-guidance-app/). Many of these link calculators for drug doses. Many of the drugs and treatments recommended in such apps are not available in developing countries, however such apps are widely used by postgraduate trainees and students in the increasingly connected world. There are also several MOOCS (massive online open-access courses) run by several universities on paediatric emergency topics, including Pediatric Advanced Life Support and paediatric first aid.

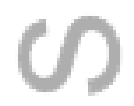

\section{Conclusion}

There is much scope for improvement in paediatric emergency care in developing countries. The obstacles are many, but improvement in service and outcomes for seriously ill children can occur with systematic quality approaches that include training in acute holistic clinical care, use of treatment guidelines, appropriate technology, essential medicines, and audit and reporting. Improvements can occur even where health care resources are very limited, and new technologies can help bridge gaps in health worker training and access to training materials, guidelines and consultation.

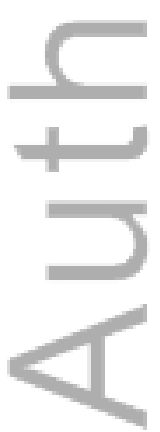




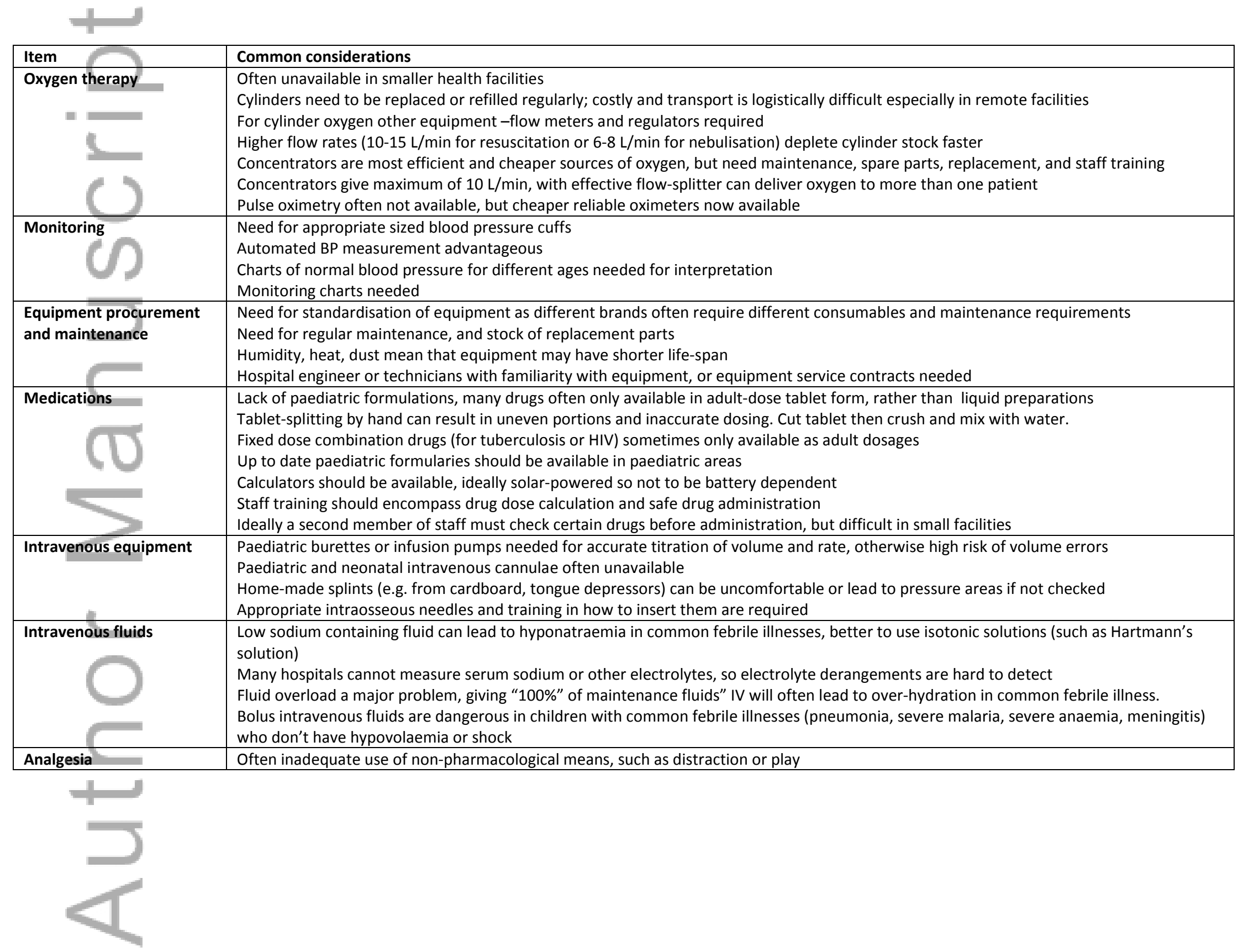

This article is protected by copyright. All rights reserved. 
Analgesia not administered early

Topical local anaesthesia insufficiently used

Procedural sedation often not used. Procedural sedation needs sufficient monitoring and observation to avoid complications

$=$ Need to teach staff to use standardized pain scoring, and have charts at point of care

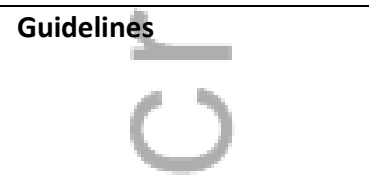

An example of evidence-based guidelines for emergency and ongoing care in resource poor settings: WHO's Pocket Book of Hospital Care for Children

Need job aids (posters, checklists) based on guidelines for prompting decision making

Lack of training

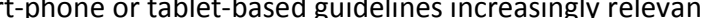

Infection control

Need for post-graduate paediatric training for nurses

Need for continuing education in paediatrics and paediatric emergencies for all cadres of health workers

Hospital-acquired infections common problem

Alcohol based hand rub disinfection or other hand hygiene facilities essential close to the points of care

Increase staff awareness of cross-infection and how to prevent it

Multi-faceted approaches (antibiotic stewardship and hand-hygiene) can reduce hospital-acquired infections even in resource-limited

settings, and reduce mortality

Lack of bacteriology means many hospital acquired infections are undetected

Health facility

infrastructure

Electricity supplies often not reliable, power surges and outages may be common, leading to equipment failure or surge-related damage

Power back-up and alternative power supply sources needed, solar power untapped resource

Water

Beds

Communication - mobile phone technology increasingly relevant

Emergency Management

Services (EMS)

Under-developed EMS is common, graded approaches to development of EMS needed

Having clear alert criteria (based on clinical signs, such as a MET or Early Warning System) for escalation important

Clear referral criteria needed

\section{Table 1. Common considerations in systems for paediatric emergency care}

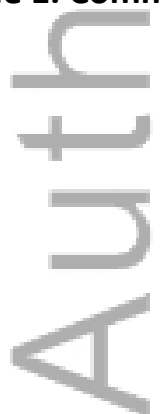

This article is protected by copyright. All rights reserved. 


\begin{tabular}{|l|}
\hline Hypovolaemia \\
\hline Severe dehydration \\
\hline Burns \\
\hline Haemorrhage / trauma \\
\hline $\begin{array}{l}\text { Septic shock (WHO defines as: fever or history of fever with tachycardia and weak pulse, capillary } \\
\text { refill >3 seconds and cold peripheries +/- low blood pressure) }\end{array}$ \\
\hline Malaria \\
\hline Bacteraemia \\
\hline Dengue \\
\hline Cardiac \\
\hline Congenital heart disease \\
\hline Myocarditis or cardiomyopathy \\
\hline Severe anaemia with cardiac failure \\
\hline Rheumatic valvular heart disease (severe AR, MR) \\
\hline Tachyarrhythmias (e.g. SVT) \\
\hline Pericardial disease (e.g. tuberculosis pericardial effusion with tamponade) \\
\hline Poisons / ingestion - mushrooms, other plants, drugs \\
\hline \\
\hline "Distributive shock" (vasodilatation) \\
\hline Anaphylaxis \\
\hline Spinal shock \\
\hline Snake bite and other envenomation \\
\hline
\end{tabular}

Table 2. Causes of paediatric shock in developing countries

Snakebite - antivenom

Anaphylaxis - adrenaline given intramuscularly or IV

SVT - vagal manoevers, digoxin, other anti-arrhythmic drugs

Poisoning - activated charcoal, gastric lavage in some cases

Severe anaemia - blood, diuretics

Haemorrhage - blood, tranexamic acid

Cardiogenic shock - inotropes

Pericardial tamponade - drainage

Textbox. Examples of specific therapy within the WHO Essential Medicines list and WHO clinical guidelines, for causes of paediatric shock

This article is protected by copyright. All rights reserved. 


\begin{tabular}{|c|c|}
\hline $\begin{array}{l}\text { Complications and considerations } \\
\text { for the child in coma }\end{array}$ & Management considerations \\
\hline Airway compromise & $\begin{array}{l}\text { Positioning } \\
\text { Suctioning } \\
\text { Guedel airway }\end{array}$ \\
\hline Pulmonary aspiration & $\begin{array}{l}\text { Positioning } \\
\text { Nasogastric feeding }\end{array}$ \\
\hline Malnutrition & $\begin{array}{l}\text { Regular NG feeding } \\
\text { Micronutrients }\end{array}$ \\
\hline Intracranial hypertension & $\begin{array}{l}\text { Nurse at incline } 30^{\circ} \text { head up } \\
\text { Careful use of mannitol }\end{array}$ \\
\hline Contractures and wasting & $\begin{array}{l}\text { Teach parent physiotherapy } \\
\text { Nutrition }\end{array}$ \\
\hline Electrolyte imbalance & $\begin{array}{l}\text { Avoid prolonged IV fluids } \\
\text { Avoid hypotonic solutions } \\
\text { Regular checking of serum } \mathrm{Na+}\end{array}$ \\
\hline Nosocomial infection & $\begin{array}{l}\text { Alcohol based hand rub disinfection } \\
\text { IV site care (remove IVs when not needed) } \\
\text { Pulmonary suctioning } \\
\text { Avoid prolonged urinary catheterisation } \\
\text { Avoid unnecessary antibiotics }\end{array}$ \\
\hline Seizure control & $\begin{array}{l}\text { Anticonvulsants: phenobarbitone / valproate / } \\
\text { levetiracetam }\end{array}$ \\
\hline Pressure areas & Regular turning, massage \\
\hline Constipation & Regular lactulose \\
\hline Gastric ulceration & $\begin{array}{l}\text { Ranitidine } \\
\text { Feeding protection }\end{array}$ \\
\hline Urinary retention & Intermittent catheterisation \\
\hline Monitoring & $\begin{array}{l}\text { Glasgow Coma Scale } \\
\text { Pulse oximetry } \\
\text { Temperature }\end{array}$ \\
\hline Diagnostic issues / imaging & $\begin{array}{l}\text { When to change treatment } \\
\text { Bacterial, TB, Cryptococcus, Encephalitis } \\
\text { Non-infectious (stroke, tumor) } \\
\text { When to do a CT scan }\end{array}$ \\
\hline Adverse treatment effects & e.g. TB drug side effects \\
\hline Communicating with parents & $\begin{array}{l}\text { Prognosis } \\
\text { Expected duration of hospitalization } \\
\text { Milestones required to be reached before discharge }\end{array}$ \\
\hline
\end{tabular}

Table 3. Care of the child in coma - details that require consideration in the first $\mathbf{2 4}$ hours and beyond

This article is protected by copyright. All rights reserved. 


\begin{tabular}{|c|}
\hline Oxygen to all beds (concentrators, cylinders) \\
\hline Pulse oximeters and sensor probes for all ages \\
\hline A method of giving CPAP \\
\hline Monitoring charts \\
\hline $\begin{array}{l}\text { Intravenous fluid administration sets (IV poles, fluid, paediatric giving sets, intravenous cannulae } \\
\text { infusion pumps, syringe pumps, etc) }\end{array}$ \\
\hline $\begin{array}{l}\text { Guidelines for: } \\
\text { 1. which children should be nursed in the HDU } \\
\text { 2. clinical management of common diseases: Pocketbook of Hospital Care for Children } \\
\text { 3. use of pulse oximetry, oxygen concentrators, CPAP, e.g. WHO's Clinical Use of Oxygen } \\
\text { 4. safe administration of blood products } \\
\text { 5. management of severe acute malnutrition } \\
\text { 6. emergency drugs list }\end{array}$ \\
\hline Blood glucose monitors \\
\hline Sphygmomanometer / automated blood pressure machine \\
\hline Equipment cupboard \\
\hline Book shelf for reference books \\
\hline Electricity outlets \\
\hline $\begin{array}{l}\text { Alcohol based hand rub disinfection, hand basins, tap and soap, visual reminders about hand } \\
\text { hygiene }\end{array}$ \\
\hline Personal protective equipment: gloves, glasses, gowns as needed \\
\hline Resuscitation trolley \\
\hline Sharps disposal containers \\
\hline Suction machines \\
\hline $\begin{array}{l}\text { Signs: } \\
\text { 1. "No Smoking" } \\
\text { 2. "Use alcohol hand rub or wash your hands before and after touching patients" }\end{array}$ \\
\hline Ward admission, audit book, computer, Paediatric Hospital Reporting Program \\
\hline
\end{tabular}

Table 4. Components of a high-dependency area in a children's ward

This article is protected by copyright. All rights reserved. 


\section{Reference List}

(1) Collier P. The Bottom Billion. 1 ed. New York: Oxford University Press; 2007.

(2) Kalter HD, Schillinger JA, Hossain M, Burnham G, Saha S, de Wit V et al. Identifying sick children requiring referral to hospital in Bangladesh. Bull World Health Organ 1997; 75(Suppl 1):65-75.

(3) World Health Organization. Hospital Care for Children: guidelines for the management of common illnesses with limited resources. 2nd ed. Geneva: WHO, ISBN 789241548373; http://www.who.int/maternal child adolescent/documents/child hospital care/en/; 2013.

(4) Nolan T, Angos P, Cunha AJLA, Muhe L, Qazi S, Simoes EAF et al. Quality of hospital care for seriously ill children in less developed countries. Lancet 2001; 357:106-110.

(5) English M, Esamai F, wasunna A, Were F, Ogutu B, wamae A et al. Assessment of inpatient paediatric care in first referral level hospitals in 13 districts in Kenya. Lancet 2004; 363:19481953.

(6) Duke T, Keshishiyan E, Kuttumuratova A, Ostergren M, Ryumina I, Stasii E et al. The quality of hospital care for children in Kazakhstan, Republic of Moldova and Russia. Lancet 2006; 367:919-925.

(7) Sa'avu M, Duke T, Matai S. Improving paediatric and neonatal care in rural district hospitals in the highlands of Papua New Guinea: a quality improvement approach. Paediatrics and International Child Health 2013; Dec 6:2046905513Y0000000081 [Epub ahead of print].

(8) Auto J, Nasi T, Ogaoga D, Kelly J, Duke T. Hospital services for children in Solomon Islands: rebuilding after the civil conflict. J Paeds Child Health 2006; 42:680-687.

(9) Molyneux E, Ahmad S, Robertson A. Improved triage and emergency care for children reduces inpatient mortality in a resource-constrained setting. Bull World Health Organ 2006; 84(314):319.

(10) Molyneux E. Paediatric emergency care in developing countries. Lancet 2001; 357:86-87. 
(11) Duke T, Wandi F, Jonathan M, Matai S, Kaupa M, Sa'avu M et al. Improved oxygen systems for childhood pneumonia: a multihospital effectiveness study in Papua New Guinea. Lancet 2008; 372:1328-1333.

(12) English M, Punt J, Mwangi I, McHugh K, Marsh K. Clinical overlap between malaria and severe pneumonia in African children in hospital. Trans $R$ Soc Trop Med Hyg 1996; 90(6):658662.

(13) Maitland K, Kiguli S, Opoka RO, Engoru C, Olupot-Olupot P, Okech SO et al. Mortality after fluid bolus in African children with severe infection. N Eng J Med 2011; 10.1056/NEJMoa1101549, published at www.NEJM.org, accessed June 5th 2011.

(14) Guiscafré H, Martínez H, Palafox M, Villa S, Espinosa P, Bojalil R et al. The impact of a clinical training unit on integrated child health care in Mexico. Bull World Health Organ 2001; 79(5):434-441.

(15) Razzak JA, Kellermann AL. Emergency medical care in developing countries: is it worthwhile? Bull World Health Organ 2002; 80:900-905.

(16) Mock CN, Tiska M, Adu-Ampofo M, Boakye G. Improvements in prehospital trauma care in an African country with no formal emergency medical services. J Trauma Inj Infect Crit Care 2002; 53:90-97.

(17) Hofmann JJ, Dzimadzi C, Lunga K, Ratsma EY, Hussein J. Motorcycle ambulances for referral of obstetric emergencies in rural Malawi: do they reduce delay and what do they cost? Int J Obstet Gynaecol 2008; 102:191-197.

(18) Sassar S, Varghese M, Kellerman A, Lormand JD. Prehospital trauma care systems. 1. 2005. Geneva, World Health Organization.

Ref Type: Report

(19) Duke T. CPAP: a guide for clinicians in developing countries. Paediatrics and International Child Health 2014; 34(1):3-11.

(20) United Nations International Labour Organization. Global estimate of health worker deficits in rural and urban areas. 1. 2015. Geneva, ILO.

Ref Type: Report

(21) Li MY, Kelly J, Subhi R, were W, Duke T. Global use of the WHO Pocket Book of Hospital Care for Children: a systematic survey. Paediatrics and International Child Health 2012; 32:E-pub July 2012; DOI 10.1179/2046905512Y.0000000017.

(22) World Health Organization. Emergency Triage Assessment and Treatment. 2014. Geneva, WHO. ISBN: 9241546875

http://www.who.int/maternal child adolescent/documents/9241546875/en/accessed December 2nd 2014.

Ref Type: Online Source

This article is protected by copyright. All rights reserved. 
(23) Ayieko P, Ntoburi S, Wagai J, Opondo C, Opiyo N, Migiro S et al. A multifaceted intervention to implement guidelines and improve admission paediatric care in Kenyan district hospitals: a cluster randomised trial. PLoS Med 2011; 8(e1001018. doi:

10.1371/journal.pmed.1001018. Epub 2011 Apr 5).

(24) Young S, Hutchinson A, Nguyen VT, Le TH, Nguyen DV, Vo TK. Teaching paediatric resuscitation skills in a developing country: introduction of the Advanced Paediatric Life Support course into Vietnam. Emerg Med Australas 2008; 20(271):275.

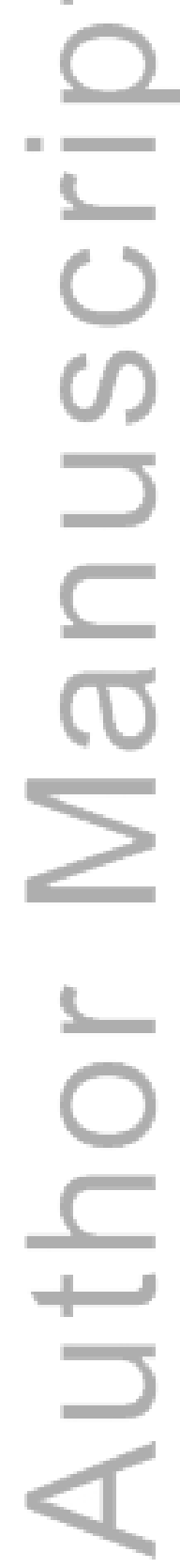

This article is protected by copyright. All rights reserved. 


\section{University Library}

\section{- M M N E R VA A gateway to Melbourne's research publications}

Minerva Access is the Institutional Repository of The University of Melbourne

Author/s:

Duke, T;Cheema, B

Title:

Paediatric emergency and acute care in resource poor settings

Date:

2016-02-01

Citation:

Duke, T. \& Cheema, B. (2016). Paediatric emergency and acute care in resource poor settings. JOURNAL OF PAEDIATRICS AND CHILD HEALTH, 52 (2), pp.221-226. https:// doi.org/10.1111/jpc.13105.

Persistent Link:

http://hdl.handle.net/11343/290878 